\title{
Cerrahi ve Immobilizasyona Bağlı Geçici Kalça Osteoporozu: Olgu Sunumu
}

\author{
Surgery and Immobilization Induced Transient Osteoporosis of the Hip: A Case Report
}

Saliha Eroğlu Demir, Emine Poyraz, Nurhan Ergül*, Teoman Aydın, Mustafa Güler

Bezmialem Üniversitesi Tıp Fakültesi, Fiziksel Tıp ve Rehabilitasyon Anabilim Dalı, İstanbul, Türkiye

*Bezmialem Üniversitesi Tıp Fakültesi, Nükleer Tıp Anabilim Dall, İstanbul, Türkiye

\section{Özet}

Kalçanın geçici osteoporozu etiyolojisi belli olmayan, kalça ağrısı ile karakterize, radyografide sınırlı osteopeni ve karakteristik Manyetik Rezonans Görüntüleme bulguları olan nadir bir durumdur. Etyopatogenezi belli değildir. Bu yazıda 25 yaşında cerrahi ve immobilizasyona bağlı kalçanın geçici osteoporozu olan hastayı sunmayı amaçladık. (Türk Osteoporoz Dergisi 2014;20: 83-5)

Anahtar kelimeler: Kalçanın geçici osteoporozu, immobilizasyon, cerrahi

\section{Summary}

Transient osteoporosis of the hip is rare condition of unclear etiology characterized by hip pain, limited osteopenia on plain radiography and characteristic magnetic resonance image findings. The etiopathogenesis is unclear. We aimed to present 25 years old patient with transient osteoporosis of the hip occurred due to surgery and immobilization in this article. (Turkish Journal of Osteoporosis 2014;20: 83-5)

Key words: Transient osteoporosis of the hip, immobilization, surgery

\section{Giriş}

Kalçanın geçici osteoporozu etiyolojisi belli olmayan, radyografide sınırlı osteopeni ve karakteristik Manyetik Rezonans Görüntüleme (MRG) bulguları olan nadir bir durumdur. İlk olarak 1959 yılında Curtiss ve Kincaid tarafından tanımlanmıştır (1).

Hastalar akut başlangıçlı ilerleyici ağrı, antaljik yürüyüş ve etkilenmiş ekstremiteyi içeren ciddi fonksiyonel dizabilite ile başvuran 3. trimester gebe ve orta yaştaki erkeklerdir (2). Semptomların başlangıcından yaklaşık bir ay sonra radyografide femur başı ve boynunda demineralizasyon ortaya çıkar. Alt ile sekiz ay sonra normal radyolojik görünüme paralel olarak semptomlar kendiliğinden iyileşir (3).

\section{Olgu}

Yirmi beş yaşında erkek hasta 20 gündür devam eden ani başlangıçı ve medikal tedaviye cevap vermeyen sol kalça ağrıs nedeniyle polikliniğimize başvurdu. Hastanın ağrısı hareket ile artıp, istirahat ile azalmaktaydı. Gece ağrısı yoktu.

Hastaya 14 yı önce trafik kazası sonrası sol femur diafiz kırığ nedeniyle plak ve vida ile osteosentez yapılmıştı. Hasta bundan sonraki 4 sene içinde 4 kez düzeltme amaçlı opere edilmişti. On yıl önce dizde kasılma, kilitlenme hissi başlamış ve çekilen direk grafileri normal bulunarak medikal tedavileri başlanmıştı. Bu şikayetleri zaman zaman tekrarlamakla birlikte son bir sene içinde artması nedeniyle başvurduğu ortopedi kliniğinde hastada sol dizde osteokondritis dissekans teşhis edilmiş ve bu dize artroskopik debridman yapılmıştı. Hastaya iki ay yatak istirahati ve quadriceps güçlendirme egzersizi ardından tek koltuk değneği ve bundan 15 gün sonra da tam yük ile mobilizasyon önerilmişti. Hastada iki hafta sonrasında sol kalça ağrısı başlamıştı.

Hastanın herhangi bir sistemik hastalığı, ilaç kullanım öyküsü, alkol-sigara alışkanlığı yoktu. Soygeçmişinde herhangi bir özellik saptanmadı.

Fizik muayenesinde vital bulguları stabil, sistemik muayenesi normaldi. Inspeksiyonla sol uyluk anterior ve lateralde $30 \mathrm{~cm}$ 'lik insizyon skarı mevcuttu. Yürüyüşü antaljikti. Lomber lordoz normaldi. Sol kalça abduksiyon, internal ve eksternal rotasyon kısıtlı ve ağrılıydı. Sağ kalça eklem hareket açıklıkları normaldi. Her iki bacak boyu arası fark $1 \mathrm{~cm}$ idi (sağ: 88, sol: 87). Her iki diz ve nörolojik muayene normaldi. 
Laboratuvar değerlendirmede tam kan sayımı, eritrosit sedimantasyon hızı, C-Reaktif protein, serum elektrolit düzeyleri, kalsiyum, alkalen fosfataz, parathormon, romatoid faktör, tam idrar tahlili normal sınırlardaydı.

Pelvis anteroposterior direk grafisi normal olarak değerlendirildi. Kalça MRG'de sol femur baş ve boyun kısmında T1 ağırlıklı görüntülerde hipointens, yağ baskılı T2 görüntülerde hiperintens sinyal özelliği gösteren kemik iliği ödemi saptandı (Resim 1). Yirmi mCi Tc-99m MDP ile yapılan tüm vücut sintigrafisinde sol femur başına uyan alanda orta düzeyde artmış aktivite tutulumu tespit edildi (Resim 2).

Hastaya yapılan tüm tetkik ve kliniğiyle kalçanın geçici osteoporozu (KGO) tanısı konuldu. Alendronat sodyum $70 \mathrm{mg}$ haftada bir gün, kalsiyum 1000 mg/gün üç ay süreyle verildi. İstirahat, kalça çevresi güçlendirme egzersizleri verilerek tek koltuk değneği ile mobilizasyon önerildi. Hastanın şikayetleri ve bulguları üç ay içinde tamamen düzeldi.

\section{Tartışma}

Kalçanın geçici osteoporozu literatürde oldukça az sayıda bildirilen nadir bir klinik sendromdur. 1955'e kadar KGO olarak

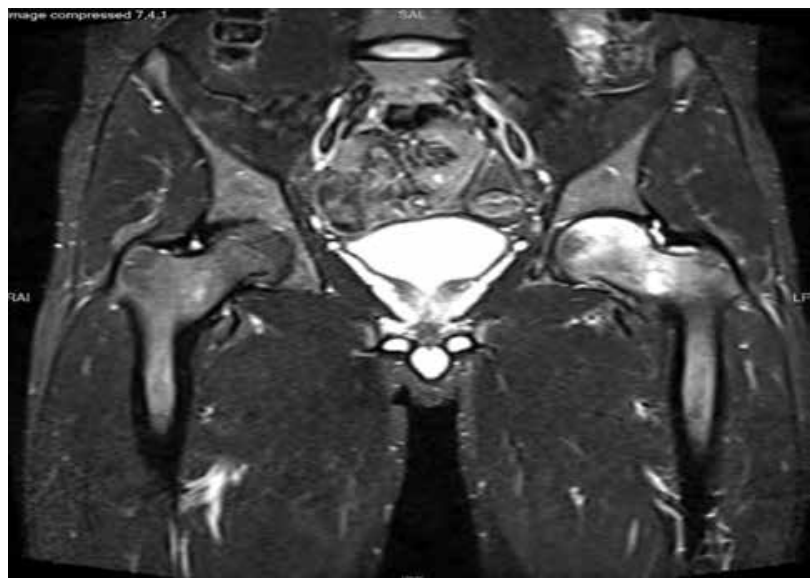

Resim 1. Kalça $M R G^{\prime}$ de sol femur baş ve boyun kısmında yağ baskılı T2 görüntülerde hiperintens sinyal özelliği gösteren kemik iliği ödemi

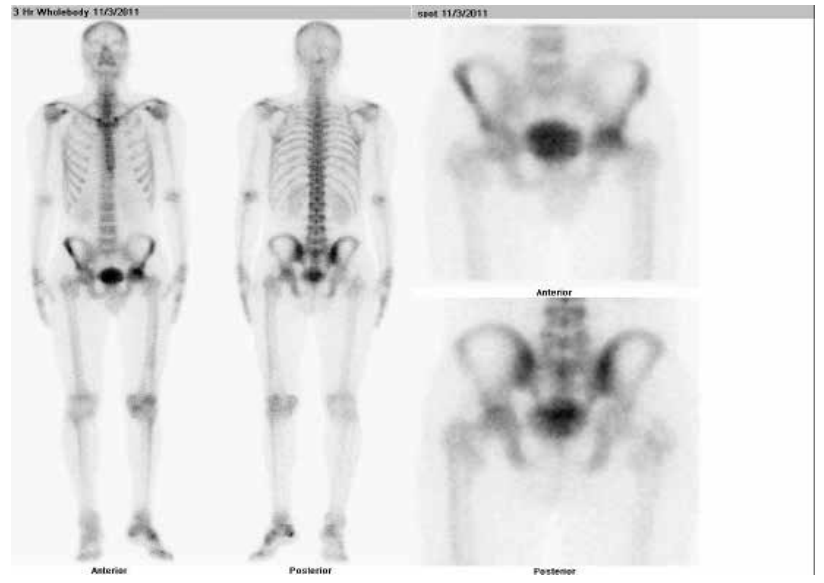

Resim 2. Kemik sintigrafisinde kan akımı ve kan havuzu fazlarında sol femur başında orta düzeyde yoğun artmış aktivite tutulumu tanımlanan yaklaşık 500 olgu bildirilmiştir. Fakat MRG'nin rutin kullanıma girmesiyle daha fazla sayıda tanı konmakta ve olgu sayıları hızla artmaktadır. Literatürdeki kadın erkek oranı 1:1,7 ve 1:5 arasında değişmektedir $(4,5)$. Genç orta yaş erkekler ve 3. trimester gebelerde daha sık görülmektedir.

Geçici osteoporozda kalça en sık tutulan eklem olmasına rağmen diz, ayak, ayak bileği, el ve diğer eklemlerde de görülebilir (6-8). KGO'nun sadece \%25'inde bir neden bulunmakla birlikte etiyolojisi tam olarak bilinmemektedir. Akgün ve ark.'nın bildirdiği 8 olgudan yalnızca ikisinde hipotiroidi ve alkolizmden bahsedilmiştir (9). Osteogenezis imperfekta, C vitamini eksikliği, hiperhomosisteinemi, şiddetli generalize osteoporoz ile birlikte bildirilen olgular da mevcuttur (7,10-12). Azmy ve ark.'nın yaptığı retrospektif bir çalışmada ise $17 \mathrm{KGO}$ lu hastanın \%65'inin doktor olduğu ve hastanın mesleğinin KGO'da risk faktörü olabileceğini bildirmişlerdir (13).

Lequesne ise 1968 'de $10 \mathrm{KGO}$ olgusu bildirmiş ve KGO'nun Sudeck atrofisinin travmatik olmayan bir varyantı olduğunu düşünmüştür (14). Bununla birlikte Sudeck atrofisinde görülen şişme, deri değişiklikleri ve diğer bulguların çoğunlukla KGO'da görülmemesi KGO'nun Sudeck atrofisinden farklı bir hastalık olduğunu düşündürmüştür. Bizim olgumuzda da hastanın uzun süre immobilize olması KGO'nun Sudeck atrofisinin bir varyantı olması düşüncesini akla getirmekle birlikte Sudeck atrofisinin klinik özelliklerini göstermemesi immobilizasyonun KGO'da bir neden olacabileceğini akla getirmiştir.

Kalça ağrısının ayırıcı tanısında inflamatuar eklem hastalıkları, septik artri, primer veya metastatik karsinomlar, pigmente villonoduler sinovit, sinovyal kondromatozis, femur boyun stres fraktürü ve osteonekroz vardır. Bu hastalıkların başlangıç semptomları KGO'ya benzerdir (3).

KGO'da kalça ağrısı genellikle akut başlangıçıdır. Travma hikayesi çoğunlukla yoktur. Ağrı istirahatle azalıp hareketle artar. Yürümede zorlanma ve antaljik yürüyüş ortaya çıkabilir.

Fizik muayenede özellikle kalçanın abduksiyon ve rotasyonları kısıtlanmış olabilir. Laboratuvar bulguları genellikle normaldir (15).

KGO'da karakteristik radyografik görünüm genellikle semptomların başlangıından dört ile sekiz hafta arasında oluşur. Eklem aralığı ise daima korunur $(3,16)$. Bizim olgumuzda olduğu gibi semptom başlangıcından 15 gün sonra radyografi normal olarak değerlendirilebilir.

KGO; 3 klinik evrede değerlendirilir:

1. Faz: Kalça ağrısı hızla artar ve eklem fonksiyonları bozulur, grafiler normaldir, MRG'de kemik iliği ödemi gözlenir. Bir-iki ay kadar sürer.

2. Faz: Semptomlar plato çizer, grafide osteoporoz ve demineralizasyon görülür, eklem aralığı korunmuştur. İki-üç ay sürer.

3. Faz: Semptomlarda gerileme olur, 6 ay ve sonrasını kapsar ve sekel kalmaz, radyolojik iyileşme daha uzun sürebilir (5).

MRG'de proksimal T1 ağılıklı görüntülemede düşük sinyal yoğunluğu ve T2 ağırlıklı görüntülemede yüksek sinyal yoğunluğu gösteren kemik iliği ödemi görülür $(4,17)$. Ayrıca Ergün ve 
ark.'nın yaptığı bir çalışmada MRG'de saptanan subkondral kırık varlığı ve boyutu ile kemik iliği ödemi yaygınlığının klinik bulguların düzelme süresini etkilediği gösterilmiştir (18). Ayrıca MRG'de rastlanan kemik iliği ödemi $K G O$ 'da görülebildiği gibi kalçanın avasküler nekrozunda (AVN) da görülebilir. Bu iki hastalığın prognozları arasındaki farklılıkları nedeniyle ayırıcı tanılarının mümkün olduğunca erken yapılması önemlidir. KGO'da semptomatik ve radyolojik tam düzelme meydana gelirken AVN'de klinik ve radyolojik tablo sürekli kötüye gider ve genellikle cerrahi tedavi gerektirir. KGO'da tutulum, genellikle femurun proksimaline (baş-boyun, bazen intertrokanterik bölge) yayllır, lezyon homojendir. AVN'de ise homojenite yoktur, daha çok femur başının anterosuperior bölgesinde subkondral segmental veya fokal tutulum görülür. Direkt radyografide femur proksimalinde görülen osteopeni KGO için karakteristiktir. AVN için patognomonik olan subkondral kollaps (hilal işareti) KGO'da görülmez (5).

KGO'da kemik sintigrafisinde nonspesifik olmakla birlikte femur baş ve boynunda her üç fazda da diffuz ve homojen artmış tutulum vardır (19). Klinik düzelme ile birlikte bulgular normale döner.

KGO tedavisinde yatak istirahati, ekleme yük verilmesinin azaltılması ile birlikte steroid olmayan anti inflamatuar ilaçlar ve analjezikler kullanılmaktadır. Hastanın ağrısının azalması ile birlikte eklem hareket açıklığı ve güçlendirme egzersizleri verilerek istirahate bağlı oluşabilecek kontraktür ve kas güçsüzlüğü önlenmeye çalışlır. Aralıklı traksiyon uygulaması ise eklem effüzyonuna bağı fleksiyon deformitesini önlemeye yardımcı olur fakat gebe kadınlarda kullanılmaz (20).

Son zamanlarda bifosfanatlar (alendronat, ibandronat, neridronat), teriparatid ve kalsitonin de KGO tedavisinde kullanılmaktadır (21-25).

Biz bu yazımızda genç, aktif, erkek hastada ani başlangıçlı kalça ağrısında KGO'nun düşünülmesi gerektiği gibi aynı şikayetlere sahip immobil bir hastada da akla getirilmesi gerektiğini vurgulamak istedik.

\section{Kaynaklar}

1. Bin Abdulhak AA, Ba-Mougadam FA, Al-Nakshabandi NA, Al-Tannir MA. Transient osteoporosis of the hip/bone marrow edema syndrome with soft tissue involvement: a case report. Oman Med J 2011;26:353-5.

2. Nacır B, Öner AY, Poçan S. Genç erkek olguda kalçanın geçici osteoporozu: olgu sunumu. Osteoporoz 2008;14:35-9.

3. Domachevsky L, Keynan Y, Militianu D, Goldenberg I, Adir Y. Transient osteoporosis associated with hyperhomocystinemia: a possible role for hyperbaric oxygen therapy. Undersea Hyperb Med 2004;31:275-9.
4. Karantanas $\mathrm{AH}$. Acute bone marrow edema of the hip: role of MR imaging. Eur Radiol 2007;17:2225-36.

5. Güzel R, Başaran S. Kalçanın geçici osteoporozu. Türk Fiz Tıp Rehab Derg 2009;55 Özel Sayı 1:41-5.

6. Ververidis AN, Drosos GI, Kazakos KJ, Xarchas KC, Verettas DA. Bilateral transient bone marrow edema or transient osteoporosis of the knee in pregnancy. Knee Surg Sports Traumatol Arthrosc 2009;17:1061-4.

7. Trevisan C, Ortolani S, Monteleone M, Marinoni EC. Regional migratory osteoporosis: a pathogenetic hypothesis based on three cases and a review of the literature. Clin Rheumatol 2002;21:41825.

8. Bircher C, Afors K, Bircher M. Transient osteoporosis of the hip in pregnancy resulting in bilateral fracture of the neck of the femur. Int J Gynaecol Obstet 2012;116:176-7.

9. Akgün K. Geçici bölgesel osteoporozlu olguların uzun dönem sonuçları. Osteoporoz Dünyasından 2002;8:136-140.

10. Karagkevrekis CB, Ainscow DA. Transient osteoporosis of the hip associated with osteogenesis imperfecta. J Bone Joint Surg $\mathrm{Br}$ 1998;80:54-5

11. Rodriguez S, Paniagua O, Nugent KM, Phy MP. Regional transient osteoporosis of the foot and vitamin C deficiency. Clin Rheumatol 2007;26:976-8.

12. Hadidy AM, Al Ryalat NT, Hadidi ST, Tarawneh ES, Hadidi MT, Samara OA, et al. Male transient hip osteoporosis: are physicians at a higher risk? Arch Osteoporos 2009;4:41-5.

13. Lequesne M. Transient osteoporosis of the hip. a nontraumatic variety of Südeck's atrophy. Ann Rheum Dis 1968;27:463-71.

14. Guerra JJ, Steinberg ME. Distinguishing transient osteoporosis from avascular necrosis of the hip. J Bone Joint Surg Am 1995;77:616-24.

15. Arayssi TK, Tawbi HA, Usta IM, Hourani MH. Calcitonin in the treatment of transient osteoporosis of the hip. Semin Arthritis Rheum 2003;32:388-97.

16. Kaplan SS, Stegman CJ. Transient osteoporosis of the hip. A case report and review of the literature. I Bone Joint Surg Am 1985;67:490-3.

17. Bezer M, Gökkuş K, Kocaoğlu B, Erol B, Güven O. Transient osteoporosis of the hip in pregnancy: a report of three cases. Acta Orthop Traumatol Turc 2004;38:229-32.

18. Ergun $T$, Lakadamyali $H$. The relationship between MRI findings and duration of symptoms in transient osteoporosis of the hip. Acta Orthop Traumatol Turc 2008;42:10-5.

19. Kotevoğlu N, Şahin F, Deniz E, Taşpınar Ş, Kuran B. Kalçanın geçici osteoporozu: olgu sunumu. Romatizma 2008;23:31-4.

20. Diwanji SR, Cho YJ, Xin ZF, Yoon TR. Conservative treatment for transient osteoporosis of the hip in middle-aged women. Singapore Med J 2008;49:17-21.

21. Kibbi L, Touma Z, Khoury N, Arayssi T. Oral bisphosphonates in treatment of transient osteoporosis. Clin Rheumatol 2008;27:52932.

22. Ringe JD, Dorst A, Faber $\mathrm{H}$. Effective and rapid treatment of painful localized transient osteoporosis (bone marrow edema) with intravenous ibandronate. Osteoporos Int 2005;16:2063-8.

23. La Montagna G, Malesci D, Tirri R, Valentini G. Successful neridronate therapy in transient osteoporosis of the hip. Clin Rheumatol 2005;24:67-9.

24. Fabbriciani G, Pirro M, Manfredelli MR, Bianchi M, Sivolella S, Scarponi AM, et al. Transient osteoporosis of the hip: successful treatment with teriparatide. Rheumatol Int 2012;32:1367-70.

25. Şendur ÖF, Gürer G, İyiyapıcı A. Geçici kalça osteoporozunun bir erkek olgu eşliğinde irdelenmesi. Osteoporoz Dünyasından 2006;12:15-7. 